\title{
Climate panel confirms human role in warming, fights off oil states
}

London. The scientific consensus on global warming took a further step forward last week when the United Nations' main advisory panel endorsed a scientific report concluding that "the balance of evidence suggests that there is a discernible human influence on global climate".

But even this conclusion, reached by Working Group 1 of the Intergovernmental Panel on Climate Change (IPCC), remains controversial, this time over an instruction to authors of the report to make last-minute revisions in the text, a move that some claim might contravene the IPCC's guidelines.

The call for modifications stemmed from bitter argument during a three-day meeting in Madrid as experts from IPCC countries sought to agree a summary of the working group's report collating scientific data on climate change. Delegates from two oilproducing nations, Saudi Arabia and Kuwait, both of which feel threatened by any curbs on the use of oil, argued at length that the summary should contain language emphasizing what they claimed to be the 'uncertain' nature of recent evidence pointing to a human effect on climate.

Other delegates disagreed. But after eight and a half hours of deadlock, they conceded to a footnote in the summary stating that "two countries" considered that recently published evidence showing a correspondence between the results of climate models and observations of climate change should be regarded only as "preliminary".

The footnote request was granted partly on the grounds that one chapter of the full report also suggests that some of the new studies on climate change have large caveats and have yielded preliminary evidence of a human effect on climate.

Mohammad Al-Sabban, an adviser to the Saudi minister of petroleum based in Jeddah and head of the kingdom's delega-

\section{Argentina may host cosmic ray detector}

Paris. Argentina has been chosen as the proposed site of the southern half of a giant, twin-location cosmic-ray observatory being put forward by an international panel of physicists. Meeting in Paris two weeks ago at the United Nations Educational, Scientific and Cultural Organization (Unesco), which has already provided $\$ 100,000$ for a design study of the planned observatory, scientists from 19 countries decided that the detector, which would cover a total area of 3,000 square kilometres, should be built in Argentina's Mendoza province.

tion to the IPCC, says he agrees that the evidence for global warming is beginning to accumulate. "But to attribute this solely to human activity is too simplistic."

But Tom Wigley, senior scientist at the US National Center for Atmospheric Research in Boulder, Colorado, a lead author of the chapter concerned, says the word 'preliminary' is used in the chapter in

\section{IMAGE UNAVAILABLE FOR COPYRIGHT REASONS}

Taking cover: few dispute that rainfall will increase.

a different context. This word, he says, implies that evidence for a human effect on climate change is initial, but clear and unambiguous. "It does not mean that evidence of human influence on global climate is uncertain." Wigley is now making clarifications to the report to remove any ambiguity. "We did not realize how this word could be misinterpreted," he says.

It remains unclear whether modifications are permitted under IPCC guidelines at such a late stage. According to the guidelines, the contents of each chapter need to be peer-reviewed before publication. The government and scientific review process ended earlier this year. And the report will now be considered for adoption as part of the IPCC's Second Assessment Report at a meeting of scientists and government representatives in Rome next week.

Sir John Houghton, co-chair of IPCC Working Group 1, denies that IPCC rules are being broken. "The rules state clearly that background material must be consistent with the policy-makers' summary."

Houghton maintains that the scientific integrity of the IPCC has not been dented by the re-write. "This is not a fudge or a cover-up," says Houghton. "The compromise has been made on presentational points. If the science had been changed, I would have abandoned the process."

The summary itself has been widely praised as an authoritative document that should help to provide a firm basis for negotiations to reduce emissions of greenhouse gases at the next UN conference of the parties to the Framework
Convention on Climate Change.

The summary points out that "recent years have been among the warmest since 1860 ". It adds that global mean temperatures have increased by between 0.3 degrees and 0.6 degrees Celsius since the late nineteenth century, and that global sea levels have risen by between 10 and $25 \mathrm{~cm}$ over the past century.

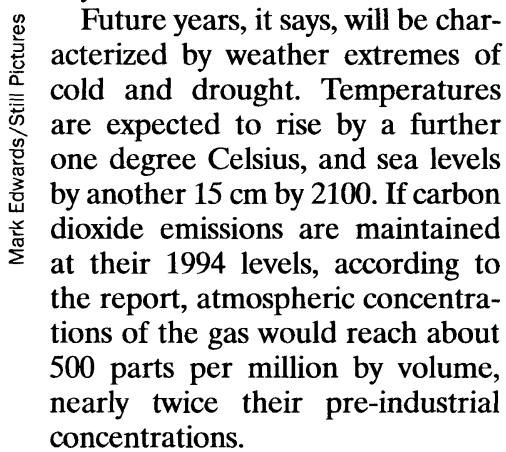

Despite the strength of these conclusions, some non-governmental organizations are concerned about suggestions that the Saudi and Kuwaiti delegates, backed, it is claimed, by the Climate Council, a major US fossil-fuel lobbying group, tried to upset the discussions and are partly responsible for large sections of the report being removed from the final summary through lack of negotiating time at last week's meeting.

Instead of the original 40-page draft document, delegates were able to approve only an 11-page version that was initially intended as an executive summary. The full summary, which contains important graphs, tables and numerical references, will now be added as a technical annexe.

Both the Saudi and Kuwaiti delegates were also criticized for failing to attend key contact group meetings - and then holding up plenary sessions by tabling extended amendments. "The situation is too serious for countries such as Saudi Arabia and Kuwait to continue trying to subvert the IPCC process," says Merylyn McKenzie Hedger, climate policy officer for the Worldwide Fund for Nature.

But Al-Sabban rejects allegations that his group tried to obstruct the negotiating process. The summary, he says, "is now balanced and cautious enough not to mislead policy-makers". Nevertheless, he says, Saudi Arabia is entitled to protect its own interests. "Saudi Arabia's oil income amounts to 96 per cent of our total exports," he says. "Until there is clearer evidence of human involvement in climate change, we will not agree to what amounts to a tax on oil."

Ehsan Masood 